\title{
Continuous-Flow Hydrogenation of 4-Phenylpyridine to 4-Phenylpiperidine with Integrated Product Isolation Using a $\mathrm{CO}_{2}$ Switchable System
}

\author{
Bernhard Barwinski ${ }^{1 \dagger}$, Pedro Migowski ${ }^{1 \dagger}$, Fabrice Gallou ${ }^{2}$, Giancarlo Franciò ${ }^{\mathbf{1}^{*}}$ and Walter Leitner ${ }^{\mathbf{1}^{*}}$ \\ ${ }^{1}$ Institut für Technische und Makromolekulare Chemie, RWTH Aachen University, Worringerweg 2, 52074 Aachen, Germany \\ ${ }^{2}$ Chemical \& Analytical Development, Novartis Pharma AG, 4056 Basel, Switzerland
}

Received: 07 April 2017; accepted: 22 April 2017

\begin{abstract}
A process comprising a continuous-flow hydrogenation reaction integrated with selective water-organic solvent biphasic extraction using $\mathrm{CO}_{2}$ as molecular switch to control partitioning was devised for the synthesis of arylpiperidines from arylpyridines. The selective hydrogenation of 4-phenylpyridine using heterogeneous carbon-supported metal catalysts was chosen as model reaction. A design-of-experiment approach was used for the identification of suitable reaction conditions under continuous-flow operation. A maximum selectivity for 4-phenylpiperidine of $96 \%$ was achieved at $87 \%$ conversion suppressing the deep hydrogenation to 4-cyclohexylpiperidine almost completely $(\leq 5 \%)$. The higher basicity of piperidines over pyridines was exploited for selective and reversible protonation of the product upon pressurization with $\mathrm{CO}_{2}$ separating it quantitatively from the remaining starting material in a water-EtOAc biphasic system. This concept enabled a fully integrated and a salt-free synthetic process using a standard $\mathrm{Pd} / \mathrm{C}$ catalyst for the hydrogenation coupled with the $\mathrm{CO}_{2}$-triggered isolation of the desired product 4-phenylpiperidine in $81 \%$ yield and $98 \%$ purity.

Keywords: Continuous flow catalysis, selective hydrogenation of pyridine in the presence of a phenyl substituent, carbon dioxide as molecular switch, aqueous biphasic selective isolation of amines triggered by carbon dioxide, reversible formation of piperidium bicarbonate
\end{abstract}

\section{Introduction}

The piperidine group is one of the most common building blocks in natural products, and a number of bioactive compounds and drugs incorporate this 6-membered $N$-heterocycle [1]. Among the several methods affording substituted piperidine derivatives, the most widely used approach involves the hydrogenation of pyridines as easily accessible starting materials [2, 3]. First systematic studies on the catalytic hydrogenation of pyridine were published already in 1928 using $\mathrm{PtO}_{2}$ (Adam's catalyst) [4]. In the 1960's, the group of Freifelder explored the reactivity of different noble metal catalysts $\left(\mathrm{PtO}_{2}, \mathrm{RuO}_{2}, \mathrm{Rh} / \mathrm{C}\right.$, and $\left.\mathrm{Rh} / \mathrm{Al}_{2} \mathrm{O}_{3}\right)$ focusing on expansion of the functional group tolerance in this reaction [5-10]. A major challenge remained the selective hydrogenation of pyridines in the presence of other aromatic groups and especially phenyl rings. Under harsh conditions $\left(>250{ }^{\circ} \mathrm{C}\right.$ and $>130 \mathrm{~atm}), \mathrm{Re}_{2} \mathrm{~S}_{7}$ can selectively hydrogenate aryl-substituted pyridines to arylpiperidines [11, 12]. Heterogeneous Pt/C [13] and $\mathrm{PtO}_{2}$ [14-17] were also used to hydrogenate arylpyridines at room temperature, and in all cases, the addition of acids was needed to avoid poisoning [18] of Pt catalysts. In general, Pt catalysts have shown little selectivity and fully hydrogenated cyclohexylpiperidines compounds were obtained, except for the case of sterically encumbered 2-phenylpyridines where 2-phenylpiperidine could be obtained in moderate to good yields of $60-90 \%$ [13-17]. Recently, Kappe et al. reported a detailed study on continuous-flow hydrogenation of pyridines using $\mathrm{Pt} / \mathrm{C}$ or $\mathrm{Rh} / \mathrm{C}$ and glacial acetic acid as solvent including one example of an aryl-substituted pyridine [19, 20]. The product isolation comprised dilution with $\mathrm{CHCl}_{3}$, addition of $\mathrm{K}_{2} \mathrm{CO}_{3}$, filtration of the formed $\mathrm{CH}_{3} \mathrm{COOK}$, and solvent evaporation.

The implementation of sustainable processes is one of the top priorities of pharmaceutical and fine chemicals manufacturers. The use of more benign solvents [21] and the exploitation of transformations with minimal E-factor [22, 23] have been long identified as valuable options for reaching this target, following

\footnotetext{
* Authors for correspondence: francio@itmc.rwth-aachen.de, leitner@itmc. rwth-aachen.de

$\dagger$ Both authors contributed equally to this study.
}

the green chemistry principles [24-26]. More recently, the utilization of continuous-flow synthetic approaches with integrated product purification have been recognized as a particularly potent tool for achieving increased material efficiency, constant product specification, and safer handling [27]. Approximately threefourths of the unit operations used in pharmaceutical companies are dedicated to purification and isolation of the reaction products [25]. The replacement of conventional workup technologies by more efficient and benign separation methodologies with a careful solvent selection [21] will positively impact also the cost-effectiveness of the overall manufacturing process [28].

In this context, the use of $\mathrm{CO}_{2}$ in green chemical synthesis and processes has emerged as an important strategy [29]. Carbon dioxide offers low environmental risk in industrial processes since it is non-toxic and non-flammable. Most applications of $\mathrm{CO}_{2}$ up to now exploit the solvent properties of $\mathrm{CO}_{2}$ at high pressure and temperatures above the critical temperature as extracting agent, e.g., for caffeine and hops aroma, and, more recently, as mobile phase in continuous-flow catalytic processes [30]. Low-pressure (up to 5 bar) gaseous $\mathrm{CO}_{2}$ can be used as a trigger to reversibly switch solvent properties for synthesis and purification [31, 32], as a $\mathrm{pH}$-controlling agent in aqueous solutions, e.g., to remediate metal contaminated wastewater via precipitation of metal carbonates [33] and also to separate basic amines from less basic compound, e.g., piperidines from pyridines [34]. Such applications do not require any specialized highpressure equipment as $\mathrm{CO}_{2}$ is used at nearly ambient conditions.

In this work, we present a selective continuous-flow hydrogenation system combined with a $\mathrm{CO}_{2}$-switchable biphasic extraction to yield phenylpiperidines starting from phenylpyridines. Several commercially available drugs such as Ritalin ${ }^{\circledR}$, Aricept ${ }^{\circledR}$, and paroxetine contain piperidine moieties bearing aryl rings, and thus, the development of an integrated process selectively affording phenylpiperidines is of broad interest for the preparation of such derivatives.

\section{Results and Discussion}

The catalytic hydrogenation of 4-phenylpyridine $(4 \mathrm{PhPy})$ (Scheme 1) was chosen as model reaction for this study. The 
Scheme 1. Catalytic hydrogenation of 4-phenylpyridine

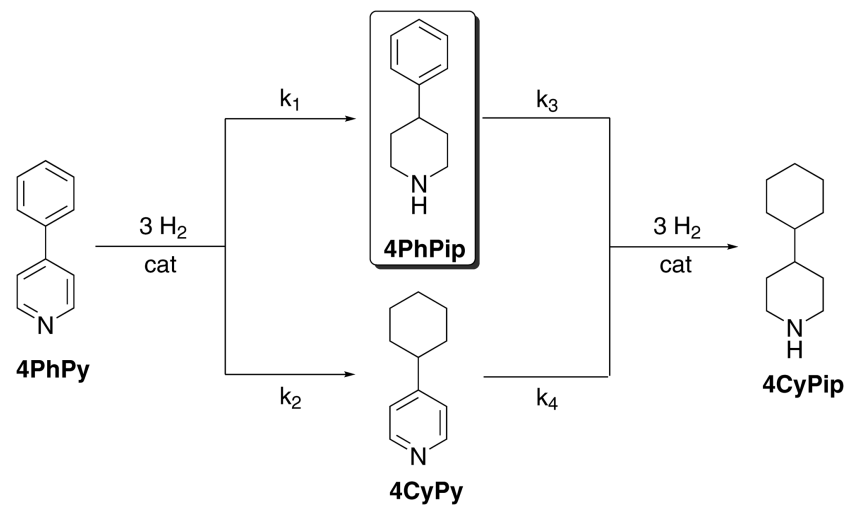

hydrogenation of $4 \mathrm{PhPy}$ (Scheme 1) in principle can yield two main products, the desired 4-phenylpiperidine (4PhPip) and the side product 4-cyclohexylpyridine (4CyPy). Both compounds can be further hydrogenated to the fully saturated 4-cyclohexylpiperidine (4CyPip). Thus, for the development of an efficient integrated process, it is necessary on the one hand to successfully address this selectivity issue with an effective catalyst using suitable conditions and, on the other hand, to develop an efficient separation procedure allowing for a facile product isolation.

Initial experiments to maximize 4PhPip yield and selectivity were performed in batch reactors. Different supported noble metal catalysts $(\mathrm{Pd}, \mathrm{Rh}, \mathrm{Pt}$, and $\mathrm{Ru})$ with a $5 \mathrm{wt} \%$ loading were investigated using ethyl acetate (EtOAc) as the solvent (Table 1). For all catalysts, carbon was chosen as support due to the promoting effect of carbonaceous materials for pyridine hydrogenation [8]. The Rh catalyst showed the highest activity for $4 \mathrm{PhPy}$ hydrogenation, and a conversion of $40 \%$ was obtained within $2 \mathrm{~h}$, with selectivities of $85 \%$ for $4 \mathrm{PhPip}, 6 \%$ for $4 \mathrm{CyPy}$, and $9 \%$ for the fully saturated side product (Table 1, entry 1 ). After $4 \mathrm{~h}$, the reaction with $\mathrm{Rh}$ reached $50 \%$ conversion, while the selectivities remained nearly constant (Table 1 , entry 2 ). The Pd catalyst showed a lower activity reaching $29 \%$ conversion after $4 \mathrm{~h}$ and selectivities of $84 \%$ for $4 \mathrm{PhPip}$ and $15 \%$ of $4 \mathrm{CyPy}$ (Table 1 , entry 3 ). It is noteworthy that, prolonging the reaction time to $8 \mathrm{~h}$, the formation of the fully hydrogenated product 4 CyPip remained lower than $1 \%$ and, even when the reaction time was doubled again to $16 \mathrm{~h}$, still less than $2 \%$ of 4CyPip was formed (Supporting Information, Table S3). Pt and $\mathrm{Ru}$ showed poor activities in the hydrogenation of $4 \mathrm{PhPy}$ as compared to $\mathrm{Rh}$ and $\mathrm{Pd}$ leading to $\leq 5 \%$ conversion after $4 \mathrm{~h}$ (Table 1, entries 5 and 7). Additionally, the reaction using $5 \% \mathrm{Ru} / \mathrm{C}$ catalyst showed a significant formation of up to $15 \%$ of 4 CyPip. The Pt-based catalyst, although being the most selective catalyst towards 4PhPip, showed only $7 \%$ conversion even after a prolonged reaction time of $65 \mathrm{~h}$, indicating a possible catalyst poisoning by the piperidine moiety [18] (Table 1, entry 8). The comparison of all reactions reaching ca. $40 \%$ conversion (Table 1 , entries 1, 4, and 6) shows that $\mathrm{Pd}$ is the most suitable catalyst since it produces negligible quantities of 4CyPip at this stage.

Additionally, several phenylpyridine derivatives substituted with donating and withdrawing groups at the 4-position of the phenyl ring were hydrogenated in batch experiments using $10 \mathrm{wt} \% \mathrm{Pd} / \mathrm{C}$ as catalyst. The presence of substituents at the phenyl group decreased the reaction rates and increased the selectivity for the pyridine ring. The investigated substrates did not show a clear trend between the electronic character of the different substituents and the selectivity of the hydrogenation, but the high selectivity for the hydrogenation of the heteroaromatic moiety was retained in all cases (see Section 3.5 in the Supporting Information for further details)

After having identified a suitable solid catalyst for the selective hydrogenation of the heteroaromatic moiety in phenyl-pyridine derivatives at reasonably high conversion, we focused on devising a facile and clean isolation procedure for $4 \mathrm{PhPip}$ from the remaining starting material and small amounts of the side product. Taking advantage of different basicity of pyridines versus piperidines, a purification and isolation procedure based on a liquid-liquid extraction in a $\mathrm{CO}_{2}$-switchable system was conceived as illustrated in Scheme $2[35,36]$. The biphasic system comprises an organic solvent containing the product mixture and an aqueous layer. The admission of $\mathrm{CO}_{2}$ to the system generates $\mathrm{H}_{2} \mathrm{CO}_{3}$ in the aqueous phase, and this weak acid protonates only the piperidine groups due to the highest basicity of this amine moiety over the pyridine (piperidine $p \mathrm{~K}_{\mathrm{a}}=11.12$; pyridine $p \mathrm{~K}_{\mathrm{a}}=5.23$ ) [37]. The formed piperidinium bicarbonate is then extracted into the aqueous phase, whereas the pyridine species remain in the organic phase.

Several selection criteria for the organic phase were defined. The solvent should be chosen from the industrially recommended solvent list [21]; it should be poorly miscible with water, and it should be suitable to be used as solvent already during the hydrogenation reaction. This last criterion allows integration of this procedure directly with the reaction step without the need of solvent replacement, thereby avoiding an additional process step and the use of additional solvent.

Therefore, water immiscible solvents of sufficiently high polarity were investigated for the hydrogenation of $4 \mathrm{PhPy}$ in batch using $\mathrm{Pd}$ supported on carbon $(\mathrm{Pd} / \mathrm{C})$ as the catalyst. 4-Methyl2-pentanol (MiBC), 2-methyltetrahydrofuran (2-MeTHF), and EtOAc were found to provide suitable reaction media for the hydrogenation of $4 \mathrm{PhPy}$ using $10 \mathrm{wt} \% \mathrm{Pd} / \mathrm{C}$ (Table 2). Under the used reaction conditions $\left(0.01\right.$ eq. $10 \mathrm{wt} \% \mathrm{Pd} / \mathrm{C}, 80{ }^{\circ} \mathrm{C}$, 30 bar $\mathrm{H}_{2}$ ), the highest catalytic activity was observed in MiBC,

Table 1. Catalyst screening for the hydrogenation of 4-phenylpyridine ${ }^{a}$

\begin{tabular}{|c|c|c|c|c|c|c|}
\hline Entry & Catalyst & $\begin{array}{l}\text { Time } \\
\text { (h) }\end{array}$ & $\begin{array}{c}\text { Conv. }^{b} \\
(\%)\end{array}$ & $\begin{array}{c}S(4 \mathrm{PhPip})^{b, c} \\
(\%)\end{array}$ & $\begin{array}{c}S(4 \mathrm{CyPy})^{b, c} \\
(\%)\end{array}$ & $\begin{array}{c}S(4 \mathrm{CyPip})^{b, c} \\
(\%)\end{array}$ \\
\hline 1 & $5 \mathrm{wt} \% \mathrm{Rh} / \mathrm{C}$ & 2 & 40 & 85 & 6 & 9 \\
\hline 2 & $5 \mathrm{wt} \% \mathrm{Rh} / \mathrm{C}$ & 4 & 50 & 86 & 6 & 8 \\
\hline 3 & $5 \mathrm{wt} \% \mathrm{Pd} / \mathrm{C}$ & 4 & 29 & 84 & 15 & $<1$ \\
\hline 5 & $5 \mathrm{wt} \% \mathrm{Ru} / \mathrm{C}$ & 4 & 4 & 69 & 19 & 12 \\
\hline 6 & $5 \mathrm{wt} \% \mathrm{Ru} / \mathrm{C}$ & 31 & 38 & 70 & 15 & 15 \\
\hline 7 & $5 \mathrm{wt}^{0} \% \mathrm{Pt} / \mathrm{C}$ & 4 & 5 & 100 & 0 & 0 \\
\hline 8 & $5 \mathrm{wt} \% \mathrm{Pt} / \mathrm{C}$ & 65 & 7 & 100 & 0 & 0 \\
\hline \multicolumn{7}{|c|}{$\begin{array}{l}{ }^{a} \text { Conditions: } 0.5 \mathrm{M} 4 \mathrm{PhPy} \text { in EtOAc, } 0.01 \text { eq. cat (related to moles of metal), } 80{ }^{\circ} \mathrm{C}, 30 \text { bar } \mathrm{H}_{2} \text {. } \\
{ }^{b} \text { Determined via }{ }^{1} \mathrm{H}-\mathrm{NMR} \text {. } \\
{ }^{c} S=\text { selectivity. }\end{array}$} \\
\hline
\end{tabular}


Scheme 2. Principle for the separation of the piperidine product from the pyridine starting material and side product in a biphasic system using $\mathrm{CO}_{2}$ as molecular switch

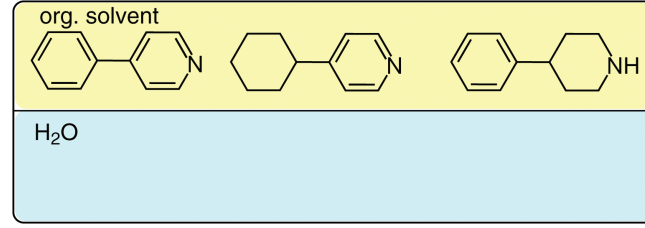

Table 2. Solvent screening in batch hydrogenation of 4-phenylpyridine using $10 \mathrm{wt} \% \mathrm{Pd} / \mathrm{C}^{a}$

\begin{tabular}{|c|c|c|c|c|c|c|}
\hline Entry & Solvent & $\begin{array}{l}\text { Time } \\
\text { (h) }\end{array}$ & $\begin{array}{c}\text { Conv. } \\
(\%)\end{array}$ & $\begin{array}{c}S(4 \mathrm{PhPip})^{b, c} \\
(\%)\end{array}$ & $\begin{array}{c}S(4 \mathrm{CyPy})^{b, c} \\
(\%)\end{array}$ & $\begin{array}{c}S(4 \text { CyPip })^{b, c} \\
(\%)\end{array}$ \\
\hline 1 & EtOAc & 24 & 49 & 90 & 9 & $<1$ \\
\hline 2 & $\mathrm{MiBC}$ & 10 & 48 & 85 & 15 & Traces \\
\hline 3 & $\mathrm{MiBC}$ & 24 & 95 & 75 & 22 & 3 \\
\hline 4 & 2-MeTHF & 16 & 54 & 84 & 14 & 2 \\
\hline 5 & 2-MeTHF & 24 & 67 & 84 & 14 & 2 \\
\hline \multicolumn{7}{|c|}{$\begin{array}{l}{ }^{a} \text { Conditions: } 0.5 \mathrm{M} 4 \mathrm{PhPy}, 0.01 \text { eq. } 10 \mathrm{wt} \% \mathrm{Pd} / \mathrm{C}, 80{ }^{\circ} \mathrm{C}, 30 \text { bar } \mathrm{H}_{2} \text {. } \\
{ }^{b} \text { Determined via }{ }^{1} \mathrm{H}-\mathrm{NMR} \text {. } \\
{ }^{c} S=\text { selectivity. }\end{array}$} \\
\hline
\end{tabular}

followed by 2-MeTHF and EtOAc (Table 2, entries 1, 2, and 4). In general, selectivities above $75 \%$ for $4 \mathrm{PhPip}$ were achieved in all cases, independently of the solvent and reaction times (Table 2 , entries 1-5). The highest selectivity at ca. $49 \%$ conversion was reached in EtOAc with 90\% (Table 2, entries 1, 2, and 4), and thus, this solvent was selected for further development.

In order to realize a fully integrated process, the hydrogenation reaction was carried out in continuous-flow mode and combined with the $\mathrm{CO}_{2}$-triggered isolation procedure. The continuous-flow hydrogenation reactions were performed on an H-Cube Pro flow system (by Thales Nano) using commercial $10 \mathrm{wt} \% \mathrm{Pd} / \mathrm{C}$ catalyst cartridges provided by the same company (for detailed information, see Section 3.8 in Supporting Information). The reaction conditions were optimized using a design of experiments (DoE) approach with a central composite design varying the reaction temperature from $100{ }^{\circ} \mathrm{C}$ to $120{ }^{\circ} \mathrm{C}$, the $\mathrm{H}_{2}$ flow from 25 to $45 \mathrm{~mL} / \mathrm{min}$, and the substrate flow from 0.5 to $1.1 \mathrm{~mL} / \mathrm{min}$ of $0.1 \mathrm{M}$ $4 \mathrm{PhPy}$ in EtOAc at a total pressure of 30 bar. It was assured that EtOAc remains liquid within the given pressure and

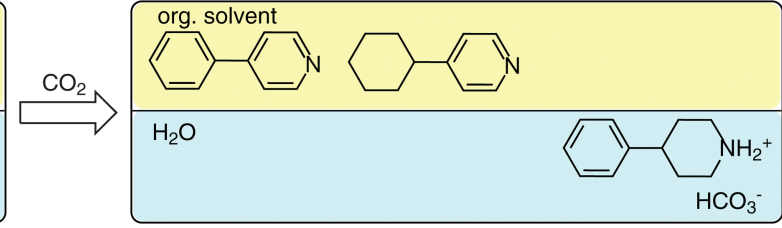

temperature regime (see Supporting Information for full details). The conditions were varied every $10 \mathrm{~min}$ after steady state was achieved, and the same conditions were applied again randomly throughout the experiment to check the catalyst stability (see Section 3.8 in Supporting Information, Table S5). Target of the optimization procedure was the maximization of $4 \mathrm{PhPy}$ conversion, maximization of $4 \mathrm{PhPip}$ selectivity, and especially minimization of 4CyPip formation, whose separation from 4PhPip would be problematic because of the almost identical basicity.

Albeit quantitative analysis was hampered by slight catalyst deactivation, the DoE approach allowed identification of optimized conditions $\left(110{ }^{\circ} \mathrm{C}\right.$, substrate flow of $0.5 \mathrm{~mL} / \mathrm{min}$, and $\mathrm{H}_{2}$ flow of $26 \mathrm{~mL} / \mathrm{min}$ ). Figure 1 shows the reaction profile of a typical continuous-flow experiment performed under such conditions. At the beginning of the experiment a minor deactivation of the catalyst was observed and the conversion decreased from $92 \%$ after $10 \mathrm{~min}$ to $85 \%$ after $60 \mathrm{~min}$. This deactivation might be caused by the adsorption of basic piperidines to partially block catalytically active Pd sites. After this induction period, conversion remained practically constant in the next hour. Remarkably, a very high selectivity towards the desired product 4PhPip was achieved under these conditions and remained nearly constant over the total time on stream. After $10 \mathrm{~min}$, the selectivity towards $4 \mathrm{PhPip}$ reached $93 \%$ and slightly increased up to $95 \%$ after $60 \mathrm{~min}$. The amount of 4CyPy was about $6 \%$ after $10 \mathrm{~min}$ and decreased further to about $4 \%$ after $60 \mathrm{~min}$. The same trend followed the formation of the fully saturated 4CyPip (slightly above $2 \%$ at the beginning of the experiment, less than $2 \%$ after $60 \mathrm{~min}$ ). It is noteworthy that the selectivities towards $4 \mathrm{PhPip}$ achieved in the continuous-flow experiments significantly surpassed the

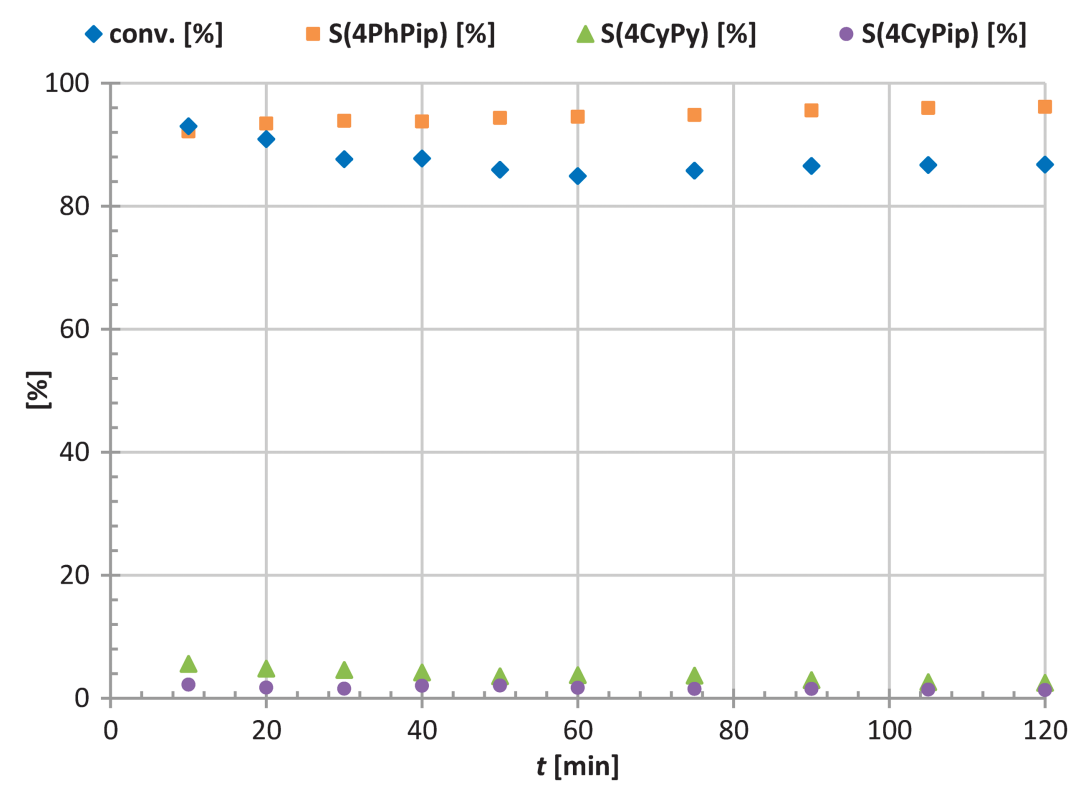

Figure 1. Hydrogenation of a $0.1 \mathrm{M}$ solution of 4-phenylpyridine in EtOAc over $10 \mathrm{wt} \% \mathrm{Pd} / \mathrm{C}$ at $110{ }^{\circ} \mathrm{C}$, at a substrate flow of $0.5 \mathrm{~mL} / \mathrm{min}, \mathrm{H}_{2}$ flow of $26 \mathrm{~mL} / \mathrm{min}$, and $30 \mathrm{bar}$ system pressure (full data in Section 3.7 in Supporting Information). Legend: conversion; $\square(4 \mathrm{PhPip})=$ selectivity for $4 \mathrm{Phpip} ; \quad S(\mathrm{CyPy})=$ selectivity for $4 \mathrm{CyPy}$, and $\triangle S(4 \mathrm{CyPip})=$ selectivity for 4CyPip 


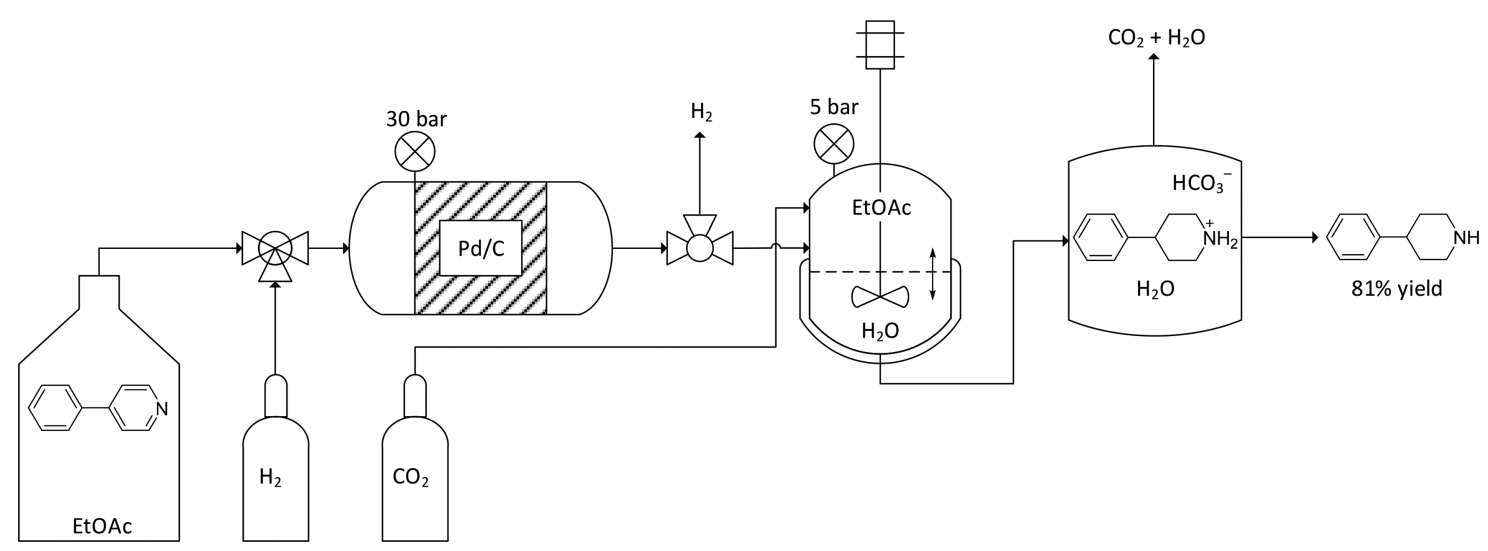

Figure 2. Process scheme for the selective continuous-flow hydrogenation of 4-phenylpyridine in EtOAc integrated with product isolation using a $\mathrm{CO}_{2}$-switchable aqueous biphasic extraction

values obtained in the batch experiments (cf. Tables 1 and 2), underlining the superiority of this methodology. The productivity of the reaction step expressed as space-time yield is 1.5 $\mathrm{g}_{\text {product }} \mathrm{mL}_{\text {catalyst }}^{-1} \mathrm{~h}^{-1}$. Similar results have been obtained in a distinct experiment over a prolonged time-on-stream of $4 \mathrm{~h}$ (see Section 3.8 in Supporting Information), showing full conversion and a selectivity of $90-92 \%$ for $4 \mathrm{PhPip}$ in the first $2 \mathrm{~h}$. Reduced conversions of $95-87 \%$ were observed in the third and fourth hour-on-stream, whereas the selectivity towards $4 \mathrm{PhPip}$ increased to up to $96 \%$.

A portion of a product mixture collected from a continuousflow experiment (see Section 3.8 in Supporting Information) containing small amounts of starting material, 4CyPy, and 4CyPip was purified using the method described above. Water was added to the ethyl acetate solution, and the mixture was stirred for $5 \mathrm{~min}$ under $\mathrm{CO}_{2}$ atmosphere (5 bar). Thereby, 4PhPip was quantitatively extracted in the water phase as the corresponding piperidinium bicarbonate. Then, the water phase was separated and the pressure was released. After evaporation of the aqueous phase, 4PhPip was obtained with a total isolated yield of $81 \%$ with $98 \%$ purity (Figure 2). It is important to note that the product was obtained as free base due to the reversibility of the protonation step. No additional salt was produced because the bicarbonate is decomposed and $\mathrm{CO}_{2}$ is removed together with water during the evaporation step. Moreover, after the phase separation, the ethyl acetate phase mostly containing unreacted starting material could be recirculated, resulting in a highly integrated and salt-free overall process.

\section{Conclusion}

We have demonstrated the selective hydrogenation of 4phenylpyridine to the corresponding 4-phenylpiperidine using a commercially available $\mathrm{Pd} / \mathrm{C}$ heterogeneous catalyst and EtOAc as ecologically benign solvent $[38,39]$. The continuousflow hydrogenation of 4-phenylpyridine to 4-phenylpiperidine was optimized using a DoE approach. High conversion (85-92\%) and selectivities (94-99\%) were obtained at a space-time yield of $1.5 \mathrm{~g}_{\text {product }} / \mathrm{mL}_{\text {catalyst }} / \mathrm{h}$. The reaction step was combined with an isolation method using $\mathrm{CO}_{2}$ as molecular switch for the selective extraction of the desired piperidine derivative from the organic to the water phase. This effective purification method does not involve by design the formation of a by-product (salt) and can be directly integrated with the reaction step using the same organic phase throughout the process. Under optimized conditions, 4-phenylpiperidine was obtained with $98 \%$ purity with a total isolated yield of $81 \%$. This atom-efficient and green methodology may hold significant potential for the synthesis of pharmaceutically relevant arylpiperidines.

\section{Experimental Section}

4.1 Batch Hydrogenation of 4-Phenylpyridine. 4Phenylpyridine (155 mg, $1.00 \mathrm{mmol}, 1$ eq.) and a carbonsupported noble metal catalyst $(5 \mathrm{wt} \% \mathrm{Rh} / \mathrm{C}, 20.6 \mathrm{mg} ; 5 \mathrm{wt} \%$ $\mathrm{Pd} / \mathrm{C}, 21.3 \mathrm{mg} ; 5 \mathrm{wt} \% \mathrm{Ru} / \mathrm{C}, 20.2 \mathrm{mg} ; 5 \mathrm{wt} \% \mathrm{Pt} / \mathrm{C}, 39.0 \mathrm{mg}$, or $10 \mathrm{wt} \% \mathrm{Pd} / \mathrm{C}, 10.6 \mathrm{mg} ; 10.0 \mu \mathrm{mol}$ of metal, 0.01 eq.) were weighed into a glass inlet for a $10 \mathrm{~mL}$ autoclave, and the solvent (2.0 mL; EtOAc, MiBC or 2-MeTHF) was added. The dispersion was stirred until 4-phenylpyridine was completely dissolved. The autoclave was purged with hydrogen and then pressurized at the desired pressure. The reaction was started via placing the autoclave into a heating cone, which was previously heated to reaction temperature, and switching on the magnetic stirrer. After the reaction, the autoclave was cooled in ice water. The pressure was carefully released, and the solution was analyzed via proton nuclear magnetic resonance (NMR) spectroscopy according to Section 2.1 in Supporting Information. The mass balance could be closed for all performed reactions. The results are given in Tables 1 and 2 .

4.2 Continuous-Flow Hydrogenation of 4-Phenylpyridine over $10 \mathrm{wt} \% \mathrm{Pd} / \mathrm{C}$. The continuous-flow reactions were carried out using a H-Cube Pro System equipped with a $30 \mathrm{~mm}$ catalyst cartridge containing about $82 \mathrm{mg} 10 \mathrm{wt} \% \mathrm{Pd} / \mathrm{C}$ as delivered by Thales Nano. The system was operated with pure EtOAc at a liquid flow of $0.3 \mathrm{~mL} / \mathrm{min}$, a hydrogen flow of $60 \mathrm{~mL} / \mathrm{min}$, at $100{ }^{\circ} \mathrm{C}$, and a system pressure of 30 bar to activate the catalyst for $1 \mathrm{~h}$. Afterwards, the system parameters were changed to $110{ }^{\circ} \mathrm{C}$, a solvent flow of $0.5 \mathrm{~mL} / \mathrm{min}$, and a hydrogen flow of $26 \mathrm{~mL} / \mathrm{min}$. When the system reached a steady state, the EtOAc was exchanged by a solution of 4-phenylpyridine $(6.22 \mathrm{~g}, 0.400 \mathrm{~mol})$ in EtOAc (359 g, $401 \mathrm{~mL}$ ) (substrate concentration of $0.1 \mathrm{~mol} / \mathrm{L}$ ). The system was operated with the substrate solution for $10 \mathrm{~min}$ before the first sample was taken to rinse the neat solvent out of the system. Afterwards, samples were collected after different time intervals (see Table S6 and S7 in Supporting Information and Figure 1). For each sample, about $6 \mathrm{~mL}$ of product solution was collected. The samples were analyzed according to Section 2.1 in Supporting Information.

4.3 Isolation of 4-Phenylpiperidine from a Reaction Solution Using Carbon Dioxide. A reaction solution as obtained from the continuous-flow hydrogenation of 4phenylpyridine was used. The reaction solution $(45.82 \mathrm{~g}, 51 \mathrm{~mL})$ contained 4-phenylpyridine (102 mg, $0.659 \mathrm{mmol}), \quad 4-$ phenylpiperidine (666 mg, $4.13 \mathrm{mmol})$, 4-cyclohexylpyridine (21.2 $\mathrm{mg}, 0.131 \mathrm{mmol})$, and 4-cyclohexylpiperidine (12.5 mg, $0.0748 \mathrm{mmol}$ ) as determined by ${ }^{1} \mathrm{H}-\mathrm{NMR}$ spectroscopy. First, the solvent was reduced using a rotary evaporator at $40{ }^{\circ} \mathrm{C}$ and 270 mbar. The resulting solution (15.69 g, $17.5 \mathrm{~mL})$ was 
transferred in a $100 \mathrm{~mL}$ glass autoclave (Büchi Miniclave), and water $(17.5 \mathrm{~mL})$ was added. The autoclave was pressurized with $\mathrm{CO}_{2}$ (5 bar). The dispersion was stirred for $5 \mathrm{~min}$ at room temperature (about $22{ }^{\circ} \mathrm{C}$ ), while the pressure was kept at 5 bar. Afterwards, the phases were allowed to separate for $20 \mathrm{~min}$, and the water phase was taken out of the autoclave via a septum while the system was kept under 5 bar $\mathrm{CO}_{2}$ atmosphere. Water was carefully removed using a rotary evaporator at $40{ }^{\circ} \mathrm{C}$ and 70 mbar, yielding a white solid. The solid was dried in a desiccator under vacuum for 4 days. 4-Phenylpiperidine was obtained as a white solid in $98 \%$ purity (GC, see Section 3.9 in Supporting Information). Yield was $653 \mathrm{mg}$ (4.05 mmol, 98\%).

\section{Supporting Information}

Electronic Supplementary Material (ESM) associated with this article is available in the online version at doi: $10.1556 /$ 1846.2017.00003.

Acknowledgments. We thank the Ministry for Innovation, Science, and Research of the State North Rhine-Westphalia (project "Conticat") and Novartis for financial support and Dr. Thomas Tacke (Evonik AG) for the kind donation of a sample of $\mathrm{Pd} / \mathrm{C}$. P.M. thanks the Alexander von Humboldt Foundation for funding.

Open Access. This article is distributed under the terms of the Creative Commons Attribution 4.0 International License (https://creativecommons.org/licenses/by/4.0/), which permits unrestricted use, distribution, and reproduction in any medium, provided the original author and source are credited, you give a link to the Creative Commons License, and indicate if changes were made.

\section{References}

1. Buffat, M. G. P. Tetrahedron 2004, 60, 1701-1729.

2. Glorius, F. Org. Biomol. Chem. 2005, 3, 4171-4175.

3. Horton, D. A.; Bourne, G. T.; Smythe, M. L. Chem. Rev. 2003, 103, 893-930.

4. Hamilton, T. S.; Adams, R. J. Am. Chem. Soc. 1928, 50, 2260-2263.

5. Freifelder, M. J. Org. Chem. 1962, 27, 4046.

6. Freifelder, M. J. Org. Chem. 1963, 28, 602-603.

7. Freifelder, M. J. Org. Chem. 1964, 29, 2895-2898.
8. Freifelder, M.; Robinson, R. M.; Stone, G. R. J. Org. Chem. 1962, 27, 284-286.

9. Freifelder, M.; Stone, G. R. J. Org. Chem. 1961, 26, 3805-3808.

10. Freifelder, M.; Wright, H. B. J. Med. Chem. 1964, 7, 664-665.

11. Ryashentseva, M. A.; Minachev, K. M.; Dorogov, V. V.; Prostakov, N. S. Chem. Heterocycl. Compd. 1972, 8, 82-84.

12. Ryashentseva, M. A.; Prostakov, N. S. Chem. Heterocycl. Compd. 1992, 28, 1229-1235

13. Kim D.-I., Deutsch, H. M.; Ye, X.; Schweri, M. M. J. Med. Chem. 2007, 50, 2718-2731.

14. Díaz, J. L.; Fernández-Forner, D.; Bach, J.; Lavilla, R. Synth. Commun. 2008, 38, 2799-2813.

15. Mach, U. R.; Hackling, A. E.; Perachon, S.; Ferry, S.; Wermuth, C. G.;

Schwartz, J.-C.; Sokoloff, P.; Stark, H. ChemBioChem 2004, 5, 508-518.

16. Overberger, C. G.; Herin, L. P. J. Org. Chem. 1962, 27, 417-422.

17. Subramanyam, C.; Chattarjee, S.; Mallamo, J. P. Tetrahedron Lett.

1996, 37, 459-462.

18. Maxted, E. B.; Walker A. G. J. Chem. Soc. 1948, 1093-1097.

19. Irfan, M.; Petricci, E.; Glasnov, T. N.; Taddei, M.; Kappe, C. O. Eur. J. Org. Chem. 2009, 1327-1334.

20. Irfan, M.; Glasnov, T. N.; Kappe, C. O. ChemSusChem 2011, 4, 300-316.

21. Prat, D.; Hayler, J.; Wells, A. Green Chem. 2014, 16, 4546-4551.

22. Sheldon, R. A. Green Chem. 2007, 9, 1273-1283.

23. Sheldon, R. A. Green Chem. 2017, 19, 18-43.

24. Gutmann, B.; Cantillo, D.; Kappe, C. O. Angew. Chem., Int. Ed. 2015, $54,6688-6728$

25. Jiménez-González, C.; Poechlauer, P.; Broxterman, Q. B.; Yang B.-S.; am Ende, D.; Baird, J.; Bertsch, C.; Hannah, R. E.; Dell'Orco, P.; Noorman, H.; Yee, S.; Reintjens, R.; Wells, A.; Massonneau, V.; Manley, J. Org. Process Res. Dev. 2011, 15, 900-911.

26. Anastas, P.; Han, B.; Leitner, W.; Poliakoff, M. Green Chem. 2016, 18, 12-13. 27. Pollet, P.; Davey, E. A.; Urena-Benavides, E. E.; Eckert, C. A.; Liotta C. L. Green Chem. 2014, 16, 1034-1055.

28. Baxendale, I. R.; Braatz, R. D.; Hodnett, B. K.; Jensen, K. F.; Johnson, M. D.; Sharratt, P.; Sherlock, J.-P.; Florence, A. J. J. Pharm. Sci. 2015, 104, 781-791.

29. Leitner, W.; Jessop, P. G. Handbook of Green Chemistry, Vol. 4; Supercritical Solvents; Wiley-VCH Verlag GmbH \& Co. KGaA: Weinheim, 2010. 30. Franciò, G.; Hintermair, U.; Leitner, W. Philos. Trans. R. Soc. London, Ser. A 2015, 373, DOI: 10.1098/rsta.2015.0005.

31. Jessop, P. G.; Mercer, S. M.; Heldebrant, D. J. Energy Environ. Sci. 2012, 5, 7240-7253

32. Jessop, P. G. Aldrichim Acta 2015, 48, 18-21.

33. Enick, R. M.; Beckman, E. J.; Shi, C.; Xu, J.; Chordia, L. Energy Fuels 2001, 15, 256-262.

34. Rieger, W. H.; Springman, L. A. REILLY TAR \& CHEM CORP, Purification of piperidines, 1959-01-13, US2868793, 1959.

35. Xiong, D.; Li, Z.; Wang, H.; Wang, J. Green Chem. 2013, 15, 1941-1948.

36. Franciò, G.; Leitner, W.; de Wispelaere, I. M.; Rheinisch Westfälische

Technische Hochschule Aachen; Verfahren zur Herstellung von Aminen; 2014 11-27, DE102013105317A1, 2014.

37. Lide, D. R. CRC Handbook of Chemistry and Physics, 85th edn.; CRC Press: Boca Raton, 2004.

38. Prat, D.; Hayler, J.; Wells, A. Green Chem. 2014, 16, 4546-4551.

39. Prat, D.; Pardigon, O.; Flemming, H.-W.; Letestu, S.; Ducandas, V.; Isnard, P.; Guntrum, E.; Senac, T.; Ruisseau, S.; Cruciani, P.; Hosek, P. Org. Process Res. Dev. 2013, 17, 1517-1525. 